\title{
The curse of the prey: Sarcoptes mite molecular analysis reveals potential prey-to-predator parasitic infestation in wild animals from Masai Mara, Kenya
}

Francis Gakuya ${ }^{1}$, Luca Rossi ${ }^{2}$, Jackson Ombui ${ }^{3}$, Ndichu Maingii, Gerald Muchemi ${ }^{3}$, William Ogara ${ }^{3}$, Ramón C Soriguer ${ }^{5}$ and Samer Alasaad ${ }^{2,5,6^{*}}$

\begin{abstract}
Background: Recently, there have been attempts to understand the molecular epidemiology of Sarcoptes scabiei, to evaluate the gene flow between isolates of $\mathrm{S}$. scabiei from different hosts and geographic regions. However, to our knowledge, a molecular study has not been carried out to assess the molecular diversity and gene flow of Sarcoptes mite in a predator/prey ecosystem.

Results: Our study revealed an absence of gene flow between the two herbivore (Thomson's gazelle and wildebeest)- and between the two carnivore (lion and cheetah)-derived Sarcoptes populations from Masai Mara (Kenya), which is in discrepancy with the host-taxon law described for wild animals in Europe. Lion- and wildebeest-derived Sarcoptes mite populations were similar yet different from the Thomson's gazelle-derived Sarcoptes population. This could be attributed to Sarcoptes cross-infestation from wildebeest ("favourite prey") of the lion, but not from Thomson's gazelle. The cheetah-derived Sarcoptes population had different subpopulations: one is cheetah-private, one similar to the wildebeest- and lion-derived Sarcoptes populations, and another similar to the Thomson's gazelle-derived Sarcoptes mite population, where both wildebeest and Thomson's gazelle are "favourite preys" for the cheetah.

Conclusions: In a predator/prey ecosystem, like Masai Mara in Kenya, it seems that Sarcoptes infestation in wild animals is prey-to-predator-wise, depending on the predator's "favourite prey". More studies on the lion and cheetah diet and behaviour could be of great help to clarify the addressed hypotheses. This study could have further ramification in the epidemiological studies and the monitoring protocols of the neglected Sarcoptes mite in predator/prey ecosystems.
\end{abstract}

Keywords: Sarcoptes scabiei, microsatellites, genetic structure, gene flow, cheetah, lion, wildebeest, Thomson?'?s gazelle, favourite prey

\section{Background}

Sarcoptes scabiei is a ubiquitous ectoparasite infecting more than 100 species of mammals, worldwide [1-3].

An epidemic can result from the introduction of a single case of scabies into crowded living conditions [4], which may result in devastating mortality in wild and

\footnotetext{
* Correspondence: samer@ebd.csic.es

${ }^{2}$ Dipartimento di Produzioni Animali, Epidemiologia ed Ecologia, Università degli Studi di Torino, Via Leonardo da Vinci 44, I-10095, Grugliasco, Italy Full list of author information is available at the end of the article
}

domestic animals [5], with huge economic losses affecting the world animal trade [6].

Numerous epidemiological studies have been reported from different human, wild and domestic populations $[7,8]$ but the epidemiology of sarcoptic mange is still not well understood and seems to differ between different areas and animal species of the world [1].

Recently, there have been attempts to understand the molecular epidemiology of the Sarcoptes mite, to evaluate the gene flow between isolates of S. scabiei from

\section{Biomed Central}


different hosts and geographic regions [9]. Walton et al. $[10,11]$, used multi-locus genotyping applied to microsatellite markers to substantiate previous findings to the effect that gene flow between scabies mite populations in human and dog hosts is extremely rare in northern Australia. Genetic differences were detected between geographically distinct populations, and even between different people in the same household. Microsatellite markers were used by Alasaad et al. [12] to describe a new phenomenon of genetic structuring among S. scabiei at the individual host skin-scale level. Host-taxon law (carnivore-, omnivore- and herbivore-derived Sarcoptes mite populations) was established for Sarcoptes mite populations in wild animals from Europe $[13,14]$. However, to our knowledge, a molecular study has not been carried out to assess the molecular diversity and gene flow of Sarcoptes mite in a predator/prey ecosystem.

Sarcoptic mange has continuously threatened wildlife populations in most of the wildlife areas in Kenya. One of the animals that, to date, has remained a preferential host for Sarcoptes mite is the cheetah (Acinonyx jubatus). The cheetah population in Kenya is estimated to be less than 1000 individuals [15]. The cheetah is now extinct in some areas within its historical and geographical range, and the remaining population is highly endangered. Among the major factors thought to have brought about the decline of the cheetah are diseases, with sarcoptic mange being placed among the leading causes of death [16]. Sarcoptes mite also affects Thomson gazelles (Gazelle thompsonii), the most important prey animal of the cheetah, and wildebeest (Connochaetes taurinus), another prey species of lions (Panthera leo) and even cheetah [17].

\section{Results}

Twenty six alleles were detected from the eight microsatellite loci. The allele count for each of the 8 loci ranged from one (Sarms36 and Sarms40, which were excluded from the analyses) to seven (Sarms34). Eleven private alleles (alleles present in only one host-derived population) were detected. The number of private alleles ranged between zero (Sarms35) and three (Sarms34 and Sarms44). The wildebeest-derived Sarcoptes population had the highest number, with five private alleles, followed by the cheetah with three and lion with two private alleles, while only one was detected from the Thomson's gazelle-derived mite population (Table 1).

For all loci examined there was no evidence of linkage disequilibrium $(P>0.05)$. Deviation from Hardy-Weinberg equilibrium (HWE) was detected in Sarms34 ( $p=$ $0.008)$, Sarms35 $(p=0.014)$ and Sarms36 $(p<0.001)$ in Thomson's gazelle-derived Sarcoptes population, and in
Table 1 Private alleles detected at the eight microsatellite loci of the four wildlife-derived Sarcoptes mite populations from Masai Mara in Kenya, together with their overall frequencies

\begin{tabular}{llcc}
\hline Locus & Allele & $\begin{array}{c}\text { Overall } \\
\text { frequency }\end{array}$ & $\begin{array}{c}\text { Animal-derived Sarcoptes } \\
\text { population }\end{array}$ \\
\hline \multirow{2}{*}{ Sarms34 } & 174 & 0.0088 & Thomson's gazelle \\
\cline { 2 - 4 } & 204 & 0.0175 & Wildebeest \\
\cline { 2 - 4 } Sarms37 & 176 & 0.0093 & Cheetah \\
\cline { 2 - 4 } & 180 & 0.0463 & Wildebeest \\
\hline Sarms41 & 236 & 0.0085 & Cheetah \\
\cline { 2 - 4 } & 240 & 0.0085 & Cheetah \\
\hline \multirow{2}{*}{ Sarms44 } & 270 & 0.0086 & Lion \\
\cline { 2 - 4 } & 276 & 0.0172 & Wion \\
\hline Sarms45 & 172 & 0.0086 & Wildebeest \\
\hline
\end{tabular}

Sarms44 $(p=0.02)$ in cheetah-derived Sarcoptes mite population.

Intra-host variation was detected in all the animals from Thomson's gazelle-, wildebeest-, and cheetahderived Sarcoptes populations, and only in one animal in lion-derived Sarcoptes mite population.

Mean number of alleles was $1.625 \pm 0.992$ (for Thomson's gazelle-), $2.375 \pm 1.409$ (for wildebeest-), $2 \pm 0.866$ (for cheetah-), and $1.875 \pm 0.927$ (for lion-derived Sarcoptes mite population). Mean expected heterozygosity was $0.20115 \pm 0.26909$ (for Thomson's gazelle-), 0.3228 \pm 0.31033 (for wildebeest-), $0.2735 \pm 0.23382$ (for cheetah-), and $0.26655 \pm 0.27041$ (for lion-derived Sarcoptes mite population).

AMOVA analysis showed differentiation among populations $\left(F_{S T}=0.24241 ; P<0.001\right)$, which indicates that the mite component populations differed greatly. $F_{S T}$ value between all wild animal-derived Sarcoptes mite populations was statistically supported, with the exception of lion- and wildebeest-derived Sarcoptes mite populations, where $F_{S T}$ value was not statistically supported. The highest $F_{S T}$ value was between Thomson's gazelle- and lion-derived Sarcoptes mite populations (Table 2).

These results were confirmed by the average number of pairwise differences (PXY) between Sarcoptes populations, which was statistically supported between all pairs of Sarcoptes populations with the exception of wildebeest- and lion-derived Sarcoptes mite populations (Table 3).

The number of migrations $(\mathrm{M}=2 \mathrm{Nm}$ for diploid data) ranged from 0.70582 (between Thomson's gazelleand lion-derived Sarcoptes mite populations) and 16.61832 (between wildebeest- and lion-derived 
Table 2 Matrix of fixation index $\left(F_{S T}\right)$ significant $P$ values, with significance level $P=0.05$ (above diagonal), and population pairwise $F_{S T}$ (below diagonal) for each pairwise comparison of four Sarcoptes mite populations from Masai Mara, Kenya

\begin{tabular}{lllll}
\hline & $\begin{array}{l}\text { Thomson's } \\
\text { gazelle }\end{array}$ & Cheetah & Wildebeest & Lion \\
\hline $\begin{array}{l}\text { Thomson's } \\
\text { gazelle }\end{array}$ & - & $<0.001^{*}$ & $<0.001^{*}$ & $<$ \\
\hline Cheetah & 0.23386 & - & $<0.001^{*}$ & $<$ \\
& & & & $0.001^{*}$ \\
\hline Wildebeest & 0.33334 & 0.19637 & - & 0.18018 \\
\hline Lion & 0.41466 & 0.15064 & 0.02921 & - \\
\hline
\end{tabular}

Sarcoptes populations). The effective number of migrations per generation was lower between the two herbivore (Thomson's gazelle and wildebeest)-derived Sarcoptes populations (0.99996), compared with the two carnivore (lion and cheetah)-derived mite populations (2.8191). The cheetah-derived S. scabiei population showed a relatively high migration rate with all the studied populations (for more details see Table 4).

Using the Bayesian assignment test of the software STRUCTURE, $\ln \operatorname{Pr}(\mathrm{X} \mid \mathrm{K})$ for the likely number of populations $\mathrm{K}$, it was consistently found $\mathrm{K}=4$, and we obtained the same results when applying Evanno et al. [18] criteria (Figure 1). Considering $\mathrm{K}=4$, herbivore (Thomson's gazelle and wildebeest)-derived Sarcoptes mite populations were separated into two different clusters, while carnivore (lion and cheetah)-derived Sarcoptes mite populations were more similar. The lionderived Sarcoptes mite population clustered with the wildebeest-derived Sarcoptes mite population. Cheetahderived Sarcoptes mite population had three different subpopulations: one subpopulation was similar to Thomson's gazelle-derived Sarcoptes mite population, one was similar to wildebeest- and lion-derived Sarcoptes mite populations, and one was cheetah-private. The Thomson's gazelle-derived Sarcoptes population

Table 3 Population average pairwise differences between four Sarcoptes mite derived populations from Masai Mara, Kenya

\begin{tabular}{lllll}
\hline & $\begin{array}{l}\text { Thomson's } \\
\text { gazelle }\end{array}$ & Cheetah & Wildebeest & Lion \\
\hline $\begin{array}{l}\text { Thomson's } \\
\text { gazelle }\end{array}$ & 1.16538 & 1.75850 & 2.31607 & 2.08393 \\
\hline Cheetah & 0.41662 & 1.51837 & 2.20000 & 1.68000 \\
\hline Wildebeest & 0.67843 & 0.38587 & 2.10989 & 1.76020 \\
\hline Lion & 0.84739 & 0.26697 & 0.05141 & 1.30769 \\
\hline
\end{tabular}

Above diagonal: average number of pairwise differences between populations (PiXY). Diagonal elements: average number of pairwise differences within population (PiX). Below diagonal: corrected average pairwise difference (PiXY$(\mathrm{PiX}+\mathrm{PiY}) / 2)$.
Table 4 Matrix of number of effective migrants per generation $(\mathrm{Nm})$ for each pairwise comparison of the four Sarcoptes mite populations from Masai Mara (Kenya)

\begin{tabular}{|c|c|c|c|}
\hline & Thomson's gazelle & Cheetah & Wildebeest Lion \\
\hline \multicolumn{4}{|c|}{ Thomson's gazelle } \\
\hline Cheetah & 1.63799 & & \\
\hline Wildebeest & 0.99996 & 2.04621 & \\
\hline Lion & 0.70582 & 2.81910 & 16.61832 \\
\hline
\end{tabular}

had two subpopulations: one similar to cheetah-derived Sarcoptes population and another private one (Figure 2).

The scatter plot of the Factorial Component Analysis (FCA), for the individuals of S. scabiei collected from the sympatric wild animals in Kenya, confirmed the results obtained by the Bayesian assignment test: Thomson's gazelle- and wildebeest-derived Sarcoptes individuals were scattered separately. Wildebeest- and lionderived Sarcoptes individuals were similar to each other. Cheetah-derived Sarcoptes individuals were the most diverse ones, distributed between Thomson's gazelle-, lion- and wildebeest-derived Sarcoptes individuals (Figure 3).

\section{Discussion}

As with other highly divergent taxa, with Sarcoptes scabiei few loci and low sample sizes are deemed sufficient to find strong population differentiation between host species $[11,14]$. The unusually high number of private alleles detected in all populations studied was the first indicator of the genetic separation and current lack of gene flow between Sarcoptes mite populations in Masai Mara.

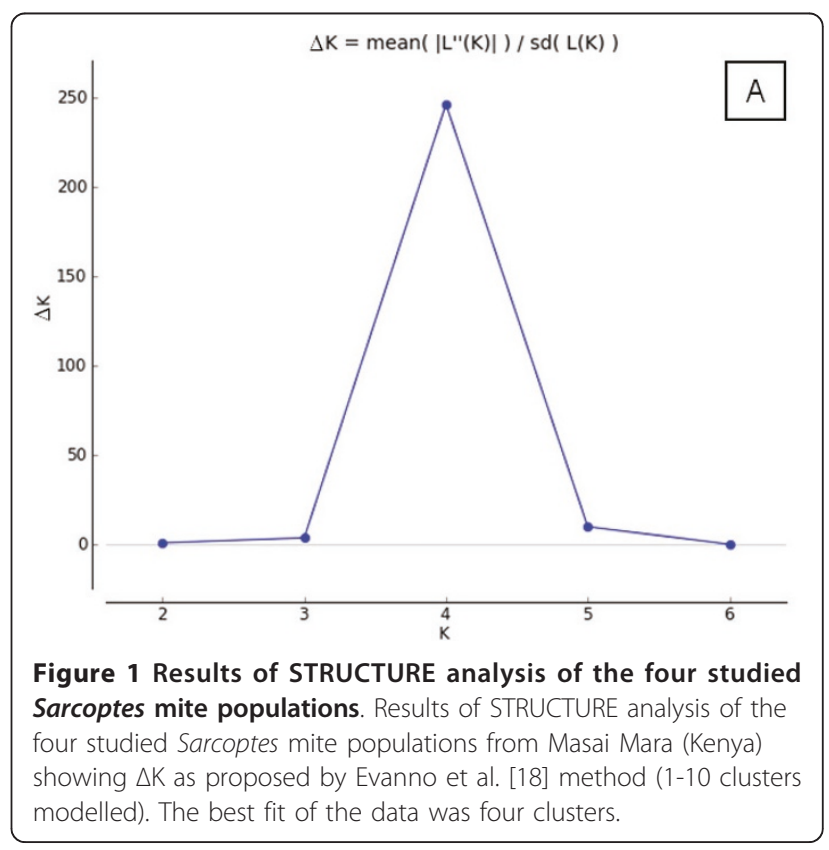




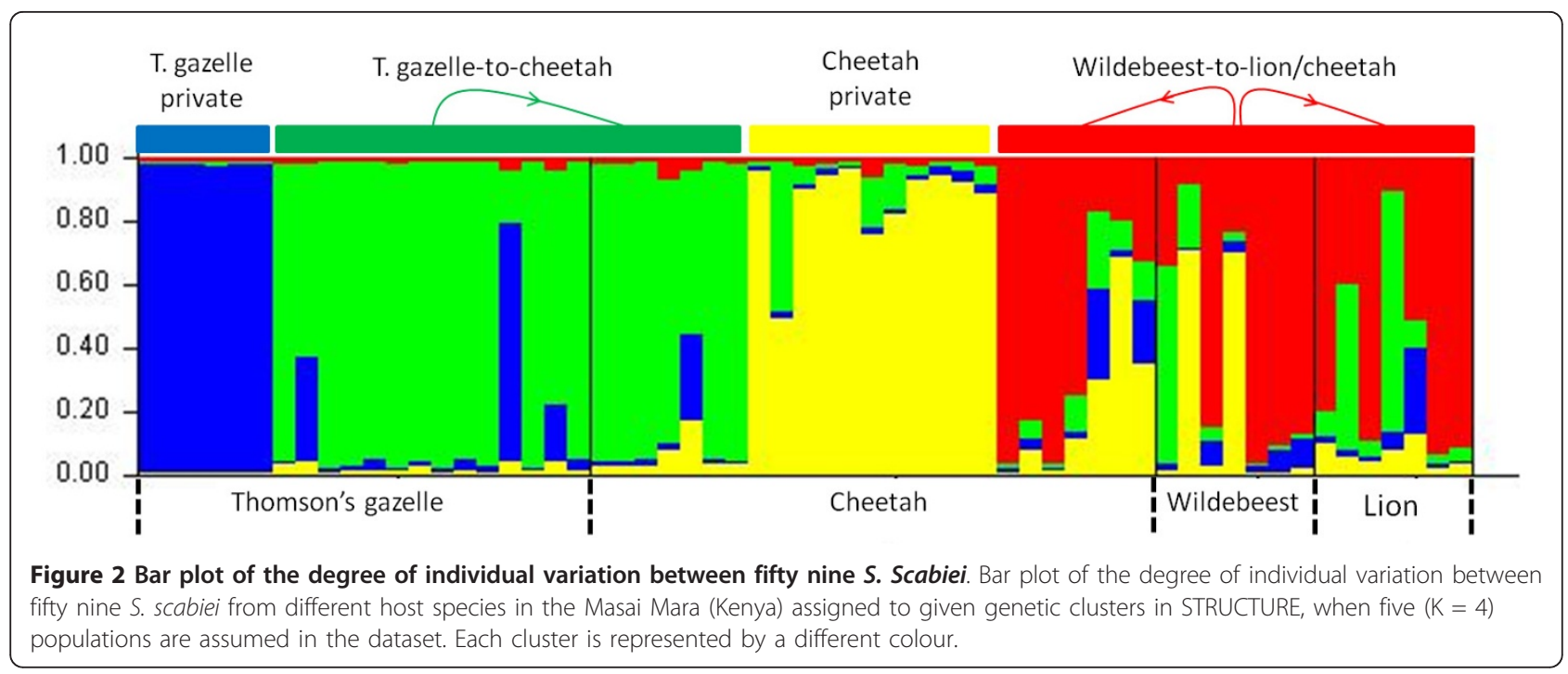

The mean number of alleles and the mean expected heterozygosity were relatively high in wildebeest- and cheetah-derived Sarcoptes mite populations, compared to lion- and Thomson's gazelle-derived Sarcoptes mite populations. This could be attributed (i) to putative higher resistance to parasite infestation $[13,19]$, (ii) to a wider range of geographical movement especially in the case of wildebeest [20-23], (iii) and/or to a higher diversity of prey species in the case of cheetah compared with lion [24-26]. Lions and Thomson's gazelles have smaller home ranges, which is limited by food availability $[27,28]$. These results were confirmed by the

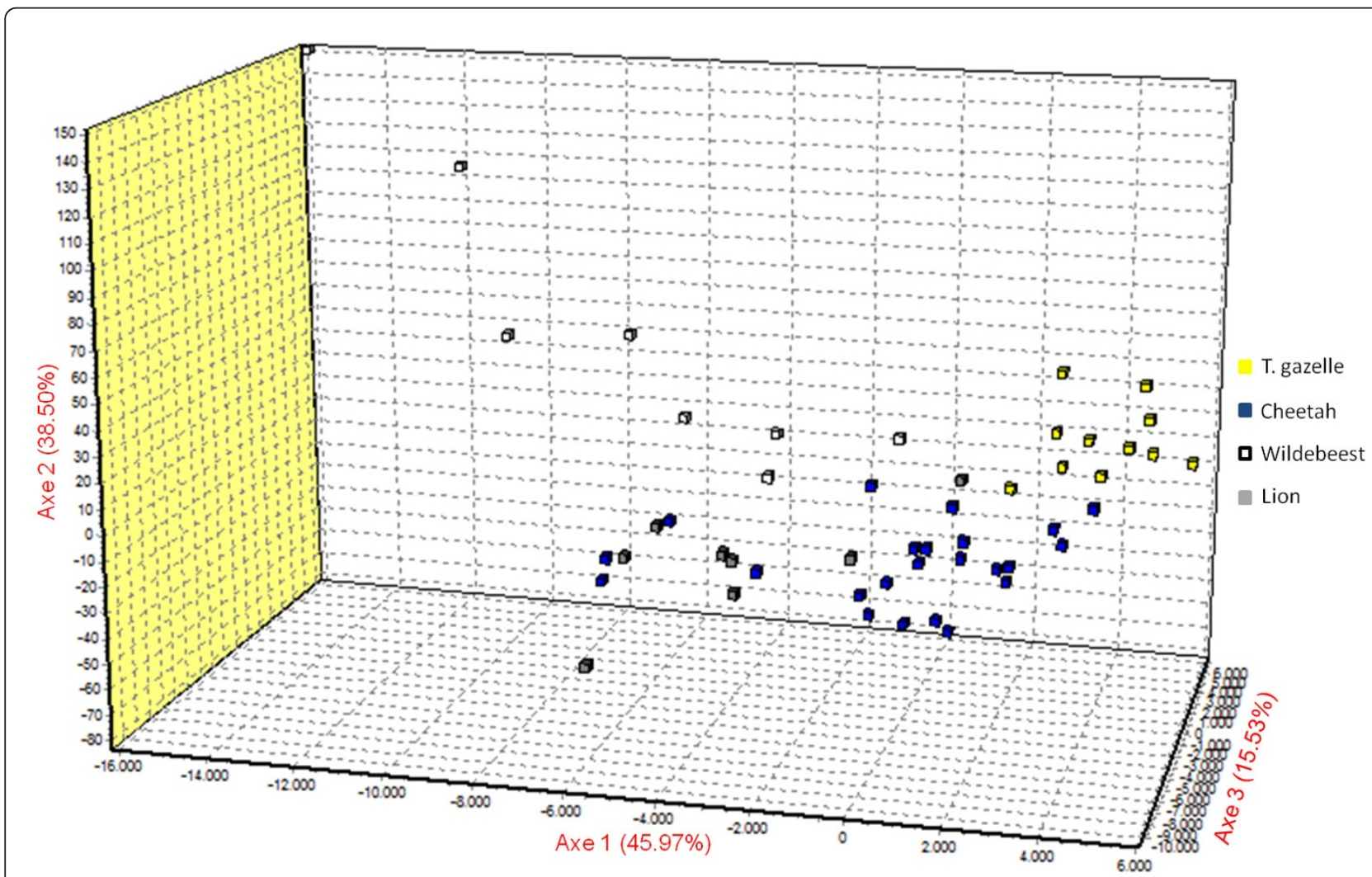

Figure 3 Factorial Component Analysis (FCA). Factorial Component Analysis (FCA) of the proportion of variation of four Sarcoptes mite populations from Masai Mara (Kenya) assigned to given genetic clusters in Genetix. 
detection of infra-host variations and the deviation from HWE in some loci from the corresponding mite populations, which could be attributed to the presence of subpopulations [12,29]. Sarcoptes mites lack free-living stages, and individual hosts, depending on their susceptibility and behaviour, are essentially ephemeral habitats providing patchy environments that hamper random mating [13,30,31].

AMOVA analysis (showing differentiation among populations) confirmed the presence of genetic differentiation and the absence of gene flow between wildlifederived Sarcoptes mite populations from Masai Mara, with the exception of lion- and wildebeest-derived Sarcoptes mite populations. This was confirmed by the Bayesian assignment test which separated the two herbivore (Thomson's gazelle and wildebeest)- and two carnivore (lion and cheetah)-derived Sarcoptes populations into different clusters, which is not in concordance with the host-taxon phenomenon described for wild animals in Europe [13,14].

All AMOVA analysis, the Bayesian assignment test (between mites), the scatter plot of the FCA (for the individuals Sarcoptes mite), and the effective number of migrations per generation showed that lion- and wildebeest-derived Sarcoptes mite populations were both similar but different from the Thomson's gazelle-derived Sarcoptes population. This could be attributed to Sarcoptes cross-infestation from wildebeest to lion, but not from Thomson's gazelle to lion. The cheetah-derived Sarcoptes population has different subpopulations: one which is private, one similar to wildebeest- and lionderived Sarcoptes populations, and another similar to Thomson's gazelle-derived Sarcoptes mite population, which could be attributed to the diet preference, since the cheetah is known to prey upon Thomson's gazelle and wildebeest, especially calves [24], in contrast to lions which are known to prey on wildebeest and rarely Thomson's gazelle $[25,26]$. There is a high probability of Sarcoptes mite transmission from the prey to the predator during the hunting process and during feeding which can lead to prey-to-predator Sarcoptes gene flow via direct transfer of S. scabiei, depending on the predator's "favourite prey". This phenomenon explains the existence of gene flow of Sarcoptes mite between lion and wildebeest, the cheetah and Thomson gazelle, and the cheetah and wildebeest. Lions preying on Thomson gazelles is quite rare especially in areas where there are other big game species [25], like in the Masai Mara ecosystem [32].

In the study reported by Rasero et al. [13] on Sarcoptes mite genetic diversity from wild animals in Europe, there was lack of interaction between carnivore, herbivore and omnivore hosts, while in a predator/prey ecosystem like Masai Mara there is evidence of such an interaction, which could lead to alterations in host- taxon phenomenon on prey-to-predator gene flow. Moreover, lions and cheetahs may preferentially select mangy preys, since the affected preys could have a reduced flight response compared with healthy individuals.

\section{Conclusions}

Bearing in mind some limitations of our study regarding the sampling size of the studied wild animals and the microsatellite panel used, our study revealed alteration in the specificity of Sarcoptes mite by its host-taxon. This alteration could be at least partially explained by predator/prey interactions. In a predator/prey ecosystem, like Masai Mara in Kenya, it seems that Sarcoptes infestation is from prey-to-predator, in relation to the predator's "favourite prey". More studies on the lion and the cheetah diet and their behaviour could be of great help to clarify the hypotheses addressed in our study, as well as more studies on Sarcoptes mites from: i) the same carnivore hosts and their "favourite preys" in different ecosystems; and ii) additional carnivore hosts (both predators and scavengers) with broader and narrower prey spectra. This study could have further ramification in the epidemiological studies and the monitoring protocols of the neglected Sarcoptes mite in predator/prey ecosystems. The effective control of sarcoptic mange in the threatened carnivores, as it the case of the cheetah in Masai Mara (which is estimated at only 61 animals; [33]), should take into account the management and control of S. scabiei in its favourite preys.

\section{Methods}

\section{Masai Mara ecosystem}

This study was carried out in the Masai Mara National Reserve and Mara Conservancy from the protected area of the Masai Mara ecosystem (1013' and 1045' S, and $34045^{\prime}$ and $35025 \mathrm{E}$ ), which covers approximately 1,850 $\mathrm{km}^{2}$ and is located at the northern tip of the Serengeti National Park (Tanzania). Rainfall increases along a southeast-northwest gradient. The terrain of the reserve is primarily open grassland with seasonal riverlets.

\section{Ethical approval}

The Committee of the Department of Veterinary and Capture Services, Kenya Wildlife Service (KWS) approved this study including the animal protocols. KWS guidelines on Wildlife Veterinary Practice-2006 were used. All veterinaries in KWS were guided by Veterinary Surgeons Act Cap 366 Laws of Kenya that regulates veterinary practice in Kenya.

\section{Specimen collection and DNA extraction}

Between 2007 and 2009 mangy animals, based on clinical observation (pruritus, alopecia, crust formation, skin 
roughening and poor body condition) were chemically immobilized, through darting using etorphine hydrochloride $\left(\mathrm{M}_{99}{ }^{\circledR} 9.8 \mathrm{mg} / \mathrm{ml}\right.$, Novartis South Africa Pty Ltd, Isando, South Africa) combined with Xylazine hydrochloride (Ilium Xylazil-100 $100 \mathrm{mg} / \mathrm{ml}$, Troy Laboratories Pty Ltd, Smithfield, Australia). The most affected area of skin was scraped with a scalpel until it bled in order to obtain hairs and crusts for parasitological examination. The scrapings were placed in universal bottles containing $70 \%$ ethanol and transported to the laboratory [34]. A total of fifty nine adult mites were collected: twenty Sarcoptes mites from three Thomson's gazelles (Eudorcas thompsonii), seven from three wildebeests (Connochaetes taurinus), twenty five from three cheetahs (Acinonyx jubatus), and seven from three lions (Panthera leo).

All mites were identified as S. scabiei on the basis of known morphological criteria [35]. The DNA of individual Sarcoptes mites was extracted using the HotSHOT Plus ThermalSHOCK technique [36]. Two blanks (reagents only) were included in each extraction to monitor for contamination.

\section{Fluorescent-based Polymerase chain reaction (PCR) analysis of microsatellite DNA}

As described by Alasaad et al. [12], eight specific Sarcoptes mite microsatellites (Sarms 34-37, 40, 41, 44 and $45)$ were used with one $8 \times$ multiplex PCR. One primer from each set was 5' labelled with 6-FAM, VIC, NED or PET $^{\circledR}$ fluorescent dye tag (Applied Biosystems, Foster City, CA, USA). Each $15 \mu \mathrm{l}$ PCR reaction mixture consisted of $3 \mu \mathrm{l}$ of the single mite DNA, together with the PCR mixture containing all primer pairs (ranging from 0.04 to $0.1 \mu \mathrm{M}$ per primer), $200 \mu \mathrm{M}$ of each dNTP, 1.5 $\mu \mathrm{l}$ of $10 \times$ PCR buffer $(200 \mathrm{mM} \mathrm{KCl}$ and $100 \mathrm{mM}$ Tris$\mathrm{HCl}, \mathrm{pH} 8.0), 1.5 \mathrm{mM} \mathrm{MgCl} 2$ and $0.15 \mu \mathrm{l}(0.5 \mathrm{U} / \mathrm{reac}-$ tion) HotStar Taq (QIAGEN, Milano, Italy). The thermal profile in a 2720 thermal cycler (Applied Biosystems, Foster City, CA, USA) was as follows: 15 min at $95^{\circ} \mathrm{C}$ (initial denaturing), followed by 37 cycles of three steps of $30 \mathrm{~s}$ at $94^{\circ} \mathrm{C}$ (denaturation), $45 \mathrm{~s}$ at $55^{\circ} \mathrm{C}$ (annealing) and $1.5 \mathrm{~min}$ at $72^{\circ} \mathrm{C}$ (extension), before a final elongation of $7 \mathrm{~min}$ at $72^{\circ} \mathrm{C}$. Fluorescent PCR amplification products were analysed using formamide with Size Standard 500 Liz (Applied Biosystems, Foster City, CA, USA) by ABI PRISM 310 Genetic Analyser with pop4. Allele calling was performed using the GeneMapper v. 4.0 software (Applied Biosystems, Foster City, CA, USA).

\section{Molecular analyses}

Expected $\left(H_{E}\right)$ and observed $\left(H_{O}\right)$ heterozygosity, linkage disequilibria (LD), and HWE tests were calculated using GENEPOP (v.3.4; [37]). Deviations from HWE and tests for LD were evaluated using Fisher's exact tests and sequential Bonferroni corrections.

The heterogeneity of genetic diversity among the different Sarcoptes mite populations was estimated by the partition of variance components (AMOVA) applying conventional $F_{S T}$ statistics using allele's frequencies as implemented in Arlequin 3.11 [38]. The analysis of relationships between mites was carried out by the Bayesian assignment test of the software STRUCTURE (v.2.3.3; [39]). Burn-in and run lengths of Markov chains were both 100000 . We ran 20 independent runs for each $\mathrm{K}$ (for $\mathrm{K}=1-10$ ). The most likely number of clusters was determined using two approaches; by estimating the posterior probability for each $\mathrm{K}$ as recommended by Pritchard et al. [39], and by using the method of Evanno et al. [18]. Finally, each of the inferred clusters was associated with the component populations of its mites.

The degree of genetic relationship among populations was further investigated with FCA as implemented in Genetix v.4.05.2 [40].

\section{Acknowledgements}

We would like to thank S. Maione, AR Molinar, R. Rasero and D. Soglia (Università degli Studi di Torino, Italy) for offering laboratory infrastructure. Thanks are also due to Dominic Mijele, Elsie Maina and John Kariuki for their assistance in field, necropsy and laboratory work. The experiments comply with the current laws of the countries in which the experiments were performed. The research was supported by The Kenya Wildlife Service, Projecto de Excelencia (Junta de Andalucia, Spain) and Juan de la Cierva Grant.

\section{Author details}

${ }^{1}$ Department of Veterinary and Capture Services, Kenya Wildlife Service, Kenya. ${ }^{2}$ Dipartimento di Produzioni Animali, Epidemiologia ed Ecologia, Università degli Studi di Torino, Via Leonardo da Vinci 44, I-10095, Grugliasco, Italy. ${ }^{3}$ Department of Public Health, Pharmacology \& Toxicology, University of Nairobi, Kenya. ${ }^{4}$ Department of Pathology and Microbiology, University of Nairobi, Kenya. ${ }^{5}$ Estación Biológica de Doñana, Consejo Superior de Investigaciones Científicas (CSIC), Avda. Américo Vespucio s/n 41092 Sevilla, Spain. ${ }^{6}$ Institute of Evolutionary Biology and Environmental Studies (IEU), University of Zürich, Winterthurerstrasse 190, 8057 Zürich, Switzerland.

\section{Authors' contributions}

$F G, L R, J N O, N M, G M, W O, R S$, and SA conceived and designed the experiments. FG and MO performed the field work experiments. FG and SA performed the molecular work. Manuscript was written by all co-authors. All authors read and approved the final manuscript.

\section{Competing interests}

The authors declare that they have no competing interests.

Received: 21 August 2011 Accepted: 6 October 2011 Published: 6 October 2011

\section{References}

1. Bornstein S, Mörner T, Samuel WM: Sarcoptes scabiei and sarcoptic mange. Edited by: Samuel WM, Pybus MJ, Kocan AA. lowa State University Press, Ames; , 2PndP 2001:107-19, (Eds) Parasitic diseases of wild mammals, ISBN 0-8138-2978- X.

2. Pence DB, Ueckermann E: Sarcoptic mange in wildlife. Rev Sci Tech 2002, 21:385-398. 
3. Alasaad S, Walton S, Rossi L, Bornstein S, Abu-Madi M, Soriguer RC, Fitzgerald S, Zhu XQ, Zimmermann W, Ugbomoiko US, Pei KJC, Heukelbach J: Sarcoptes-World Molecular Network (Sarcoptes-WMN): integrating research on scabies. Int J Inf Dis 2011, 15:294-297.

4. Obasanjo OO, Wu P, Conlon M, Karanfil LV, Pryor P, Moler G, Anhalt G, Chaisson RE, Perl TM: An outbreak of scabies in a teaching hospital: lessons learned. Infect Contr Hosp Epidemiol 2001, 22:13-18.

5. Rossi L, Fraquelli C, Vesco U, Permunian R, Sommavilla GM, Carmignola G, Da Pozzo M, Meneguz PG: Descriptive epidemiology of a scabies epidemic in chamois in the Dolomite Alps, Italy. Eur J Wildl Res 2007, 53:131-141.

6. Alasaad S, Schuster RK, Gakuya F, Theneyan H, Jowers MJ, Maione S, Molinar-Min A, Soriguer RC, Rossi L: Applicability of molecular markers to determine parasitic infection origins in the animal trade: A case study from Sarcoptes mites in wildebeest. Forensic Sci Med Pathol 2011.

7. Heukelbach J, Feldmeier H: Scabies. Lancet 2006, 367:1767-1774.

8. Green MS: Epidemiology of scabies. Epidemiol Rev 1989, 11:126-150.

9. Alasaad S, Soglia D, Spalenza V, Maione S, Soriguer RC, Pérez JM, Rasero R, Ryser Degiorgis MP, Nimmervoll H, Zhu XQ, Rossi L: Is ITS-2 rDNA suitable marker for genetic characterization of Sarcoptes mites from different wild animals in different geographic areas? Vet Parasitol 2009, 159:181-185.

10. Walton SF, Choy JL, Bonson A, Valle A, McBroom J, Taplin D, Arlian L, Mathews JD, Currie B, Kemp DJ: Genetically distinct dog-derived and human-derived Sarcoptes scabiei in scabies-endemic communities in northern Australia. Am J Trop Med Hyg 1999, 61:542-547.

11. Walton SF, Dougall A, Pizzutto S, Holt D, Taplin D, Arlian LG, Morgan M, Currie BJ, Kemp DJ: Genetic epidemiology of Sarcoptes scabiei (Acari: Sarcoptidae) in northern Australia. Int J Parasitol 2004, 34:839-849.

12. Alasaad S, Soglia D, Sarasa M, Soriguer RC, Pérez JM, Granados JE, Rasero R, Zhu XQ, Rossi L: Skin-scale genetic structure of Sarcoptes scabiei populations from individual hosts: empirical evidence from Iberian ibexderived mites. Parasitol Res 2008, 104:101-105.

13. Rasero R, Rossi L, Maione S, Sacchi P, Rambozzi L, Sartore S, Soriguer R, Spalenza V, Alasaad S: Host taxon-derived Sarcoptes mites in European wildlife animals, revealed by microsatellite markers. Biol Conserv 2010, 143:1269-1277.

14. Alasaad S, Oleaga A, Casais R, Rossi L, Molinar-Min A, Soriquer RC, Gortázar C: Temporal stability in the genetic structure of Sarcoptes scabiei under the host-taxon law: empirical evidences from wildlifederived Sarcoptes mite in Asturias, Spain. Parasit Vectors 2011, 4:151.

15. Gros PM: Status of the cheetah Acinonyx jubatus in Kenya: a fieldinterview assessment. Biol Conserv 1998, 85:137-149.

16. Weber W, Rabinowitz A: A global perspective on large carnivore conservation. Conserv Biol 1996, 10:1046-1054.

17. Mugera GM, Bwangamoi O, Wandera JG: Diseases caused by Ectoparasites I. Disease of cattle in Tropical Africa Kenya Literature Bureau Nairobi; 1979, 296-304

18. Evanno G, Regnaut S, Goudet J: Detecting the number of clusters of individuals using the software STRUCTURE: a simulation study. Mol Ecol 2005, 14:2611-2620.

19. Nejsum P, Roepstorff A, Jørgensen CB, Fredholm M, Göring HH, Anderson TJ, Thamsborg SM: High heritability for Ascaris and Trichuris infection levels in pigs. Heredity 2009, 102:357-364.

20. Estes RD: Behaviour and life history of the wildebeest (Connochaetes taurinus Burchelli). Nature 1966, 212:999-1000.

21. Creel S, Creel MN: Home ranges and habitat selection. In The African wild dog behaviour, ecology and conservation. Edited by: Creel S. and Creel M.N. Princeton University Press, 41 street, Princeton, New Jersey 08540; 2002:36-65.

22. Broomhall LSS, Mills MGL, du Toit JT: Home range and habitat use by cheetahs (Acinonyx jubatus) in Kruger National Park. J Ecol 2003, 261:119-128.

23. Houser A, Somers MJ, Boast LK: Home range use of free-ranging cheetah on farm and conservation land in Botswana. S Afr J Wild Res 2009, 39:11-22.

24. Hayward MW, Hofmeyer M, O'Brien JO, Kerley GIH: Prey preferences of cheetah (Acinonyx jubatus) (Felidae: Carnivora): Morphological limitations or need to capture rapidly consumable prey before kleptoparasites arrive. J Zool 2006, 270:615-627.
25. Owen-Smith N, Mills MG: Shifting prey selection generates contrasting herbivore dynamics within a large-mammal predator-prey web. Ecology 2008, 89:1120-1133.

26. Fryxell JM, Mosser A, Sinclair ARE, Packer C: Group formation stabilizes predator-prey dynamics. Nature 2009, 449:1041-1043.

27. Van Orsdol KG, Handy TP, Bygott M: Ecological correlates of lion social organization (Panthera leo). J Zool 1985, 206:97-112.

28. Lehmann MB, Fuston PJ, Owen CR, Slotow R: Home range utilization and territorial behaviours of lions (Panthera leo) on Korongwe Game reserve, South Africa. PLoS ONE 2008, 3:12.

29. Stern C: The Hardy-Weinberg law. Science 1943, 97:137-138.

30. Price PW: Evolutionary biology of parasites. Princeton University Press, 1980, Princeton NJ.

31. Criscione CD, Poulin R, Blouin S: Molecular ecology of parasites: elucidating ecological and microevolutionary processes. Mol Ecol 2005, 14:2247-2257, 2005.

32. Ottichilo WK, Leeuw JD, Skidmore AK, Prims HHT, Said MY: Population trends of large non-migratory wild herbivores and livestock in the Masai Mara ecosystem, Kenya, between 1977 and 1997. Afr J Ecol 2000, 38:202-216.

33. Burney DA: The effects of human activities on cheetah in the Maasai Mara region of Kenya. Msc. Thesis, University of Nairobi, Kenya; 1980.

34. Alasaad S, Rossi L, Soriguer RC, Rambozzi L, Soglia D, Pérez JM. Zhu XQ: Sarcoptes mite from collection to DNA extraction: the lost realm of the neglected parasite. Parasitol Res 2009, 104:723-732.

35. Fain A: Étude de la variabilité de Sarcoptes scabiei avec une revisiondes Sarcoptidae. Acta zool pathol Antverp 1968, 47:1-196.

36. Alasaad S, Rossi L, Maione S, Sartore S, Soriguer RC, Pérez JM, Rasero R, Zhu XQ, Soglia D: HotSHOT Plus ThermalSHOCK, a new and efficient technique for preparation of PCR-quality Sarcoptes mite genomic DNA. Parasitol Res 2008, 103:1455-1457.

37. Raymond M, Rousset F: GENEPOP version 1.2: a population genetics software for exact test and ecumenicism. J Hered 1995, 86:248-249.

38. Excoffier L: Arlequin 3.11 copyright 2006. CMPG University of Berne; 2006 [http://cmpg.unibe.ch/software/arlequin3].

39. Pritchard JK, Stephens M, Donnelly P: Inference of population structure using multilocus genotype data. Genetics 2000, 155:945-959.

40. Belkhir K: GENETIX, logiciel sous WindowsTM pour la génétique des populations, Laboratoire Génome et Populations, Université de Montpellier II. 1999 [http://www.genetix.univ-montp2.fr/genetix/intro.htm].

doi:10.1186/1756-3305-4-193

Cite this article as: Gakuya et al:: The curse of the prey: Sarcoptes mite molecular analysis reveals potential prey-to-predator parasitic infestation in wild animals from Masai Mara, Kenya. Parasites \& Vectors 2011 4:193.

\section{Submit your next manuscript to BioMed Central and take full advantage of:}

- Convenient online submission

- Thorough peer review

- No space constraints or color figure charges

- Immediate publication on acceptance

- Inclusion in PubMed, CAS, Scopus and Google Scholar

- Research which is freely available for redistribution

Submit your manuscript at www.biomedcentral.com/submit
C Biomed Central 